\title{
RANCANG BANGUN SISTEM INFORMASI AKUNTANSI PENERIMAAN KAS ATAS PENJUALAN ONDERDIL SECARA TUNAI PADA SKN MOTOR KEBUMEN
}

\author{
Dede Nurrahman \\ Sistem Informasi, Sekolah Tinggi Manajemen Informatika dan Komputer Nusa Mandiri \\ e-mail: dede.deh@nusamandiri.ac.id
}

\begin{abstract}
Abstrak
Hasil Dari Penelitian Pada SKN Motor adalah Merancang Sistem Inofrmasi Akuntansi Penerimaan Kas atas penjualan onderdil secara tunai. Dengan sistem yang dibuat dapat membantu mengurangi kesalahan penginputan kas atas penjualan onderdil secara tunai pada SKN Motor. Penelitian ini dilakukan pada SKN motor yang terletak di Jl Pahlawan No 180 Mertokondo Kebumen, SKN Motor ini didirak pada tahun 2009. SKN Motor merupakan perusahaan yang bergerak dalam bidang penjualan onderdil serta menerima jasa service. Saat ini SKN Motor masih menerapkan pencatatan menggunakan media sederhana berupa pencatatan pada buku kas masuk. Hal tersebut memungkinkan adanya kesalahan baik dalam pengolahan data penjualan maupun dalam penyusunan laporan. Sehingga dapat berpengaruh pada kurang akuratnya penerimaan kas yang di dapat pada SKN Motor. Dari penelitian tersebut penulis terinspirasi untuk merancang sistem yang dapat mempermudah pengguna dalam mengelola penerimaan kas atas penjualan onderdil pada SKN Motor dengan menggunakan komputer sebagai penunjang alat bantu. Adapun metode yang dipakai yaitu pengembangan sistem berorientasi objek dengan model waterfall.
\end{abstract}

Kata kunci: Rancang Bangun, Sistem Informasi Akuntansi, Penerimaan Kas Atas Penjualan

\begin{abstract}
The result of research on SKN Motor is designing an Accounting Information System for Cash Receipts on the sale of spare parts in cash. With the system created, it can help reduce cash input errors for the sale of cash spare parts at SKN Motor. This research was conducted on the motorbike SKN which is located on Jl Pahlawan No 180 Mertokondo Kebumen, SKN Motor was established in 2009. SKN Motor is a company engaged in the field of auto parts sales and receiving service services. At present SKN Motor still applies records using simple media in the form of recording in the cash book entry. This allows for errors both in processing sales data and in preparing reports. So that it can affect the inaccuracy of cash receipts obtained from SKN Motor. From this research the author was inspired to design a system that can facilitate users in managing cash receipts for auto parts sales at SKN Motor by using computers as supporting tools. The method used is the development of object-oriented systems with the waterfall model.
\end{abstract}

Keywords: Design and Development, Accounting Information Systems, Cash Receipt on Sales

\section{PENDAHULUAN}

Perkembangan ilmu, pengetahuan dan teknologi informasi saat ini sangat dibutuhkan oleh setiap perusahaan. Perusahaan memerlukan media untuk mengolah data menjadi informasi yang dibutuhkan. Salah satu penunjang untuk mewujudkannya adalah dengan cara mengolah data perusahaan dengan menggunakan sistem yang sudah terkomputerisasi. Seperti dibutuhkan juga dalam kegiatan operasional yang bergerak dibidang penjualan. SKN Motor merupakan bengkel servis mobil dan suku cadang mobil dan perlengkapan lainnya. SKN Motor beralamat di Jl. Pahlawan No. 180, Mertokondo, Kepatihan, Kutosari, Kec. Kebumen, Kabupaten Kebumen, Jawa Tengah 54316. Saat ini SKN Motor sudah memiliki banyak pelanggan tetap karena pelayanan servis yang ramah dan murah. Akan tetapi sistem yang diterapkan saat ini masih memiliki kelemahan karena metode pencatatan yang digunakan masih disimpan menggunakan kertas biasa sehingga memungkinkan terjadinya kerangkapan serta dapat juga menyebabkan tercecer dan hilang. Hal tersebut menyebabkan lemahnya pengendalian terhadap sistem yang berjalan pada SKN Motor saat ini. 


\section{METODE}

Metode yang di gunakan yaitu pengembangan perangkat lunak model Waterfall. (Sukamto \& Shalahuddin, 2016) Adapun tahapannya adalah:

1. Analisis Kebutuhan Perangkat Lunak (analysis)

Penulis menganalisa apa saja kebutuhan dari user yang akan dipenuhi pada Rancang Sistem Informasi Akuntansi Penerimaan Kas Atas Penjualan Onderdil Secara Tunai Pada SKN Motor Kebumen.

2. Desain (design)

Tahapan dalam proses desain pada penelitian ini meliputi rancangan sistem dengan menggunakan Diagram UML terdiri dari use case Diagram, Sequence Diagram, Deployment Diagram, dan Class Diagram.

3. Pembuatan Kode Program (coding)

Penulis menerjemahkan logika ke dalam bahasa pemrograman komputer. Bahasa pemrograman yang di gunakan adalah java.

4. Pengujian (testing)

Penulis melakukan pengujian program dengan menggunakan blackbox testing. Pengujian blackbox testing ini dimaksudkan untuk mengetahui perangkat lunak yang telah dibuat sesuai dengan yang diharapkan.

5. Pendukung (support) atau pemeliharaan (maintenance)

Dalam tahap ini penulis melakukan pengembangan yang bersifat memperbaiki dengan cara melakukan pmeriksaan dan pemeliharaan berkala pada software dan hardware yang digunakan.

Tools dari metod yang digunakan diantaranya ada:

1. Use Case Diagram

Menurut (Tohari, 2017) mengemukakan bahwa "Use Case adalah rangkaian atau uraian sekelompok yang saling terkait dan membentuk sistem secara teratur yang dilakukan atau diawasi oleh sebuah aktor".

\section{Activity Diagram}

Menurut (Sukamto A \& Shalahuddin, 2016) mengatakan bahwa "Diagram aktivitas atau activity diadram (alliran kerja) atau aktivitas dari sebuah sistem atau proses bisnis atau menu yang ada pada perangkat lunak".

3. Entity Relationship Diagram(ERD)

Menurut (Nurrahman et al., 2018) mengemukakan bahwa "Sebuah diagram ER/ER_D tersusun atas tiga komponen, yaitu entitas, atribut dan kerelasian antar entitas. Secara garis besar, entitas merupakan objek dasar yang terlibat dalam sistem. Atribut berperan sebagai penjelas entitas, sedangkan kerelasian menunjukan hubungan yang terjadi diantara dua entitas".

\section{Logical Record Structure}

Menurut (Yuniva \& Anshori, 2017) menjelaskan bahwa, "Logical Record Structure adalah repsentasi dari struktur record-record pada tabel-tabel yang terbentuk dari hasil relasi antar himpunan entitas".

5. Sequence Diagram

Menurut (Sukamto dan Shalahuddin, 2016) menjelaskan bahwa, "Diagram sekuen menggambarkan kelakuan objek pada use case dengan mendeskripsikan waktu hidup objek dan message yang dikirimkan dan diterima antar objek".

6. Deployment Diagram

Menurut (Tohari, 2017) menjelaskan bahwa, "Diagram deployment menunjukan tata letak sebuah sistem secara fisik. Diagram ini akan menampakkan bagian-bagian sofware yang berjalan pada bagian-bagian hadware yang digunakan untuk mengimplementasikan sebuah sistem dan keterhubungan anatar komponen-komponen hadware tersebut". 


\section{HASIL DAN PEMBAHASAN}

1. Tinjauan Perusahaan

SKN MOTOR adalah perusahaan yang bergerak dibidang pelayanan jasa servis mobil dan menyediakan segala macam accesories mobil. SKN MOTOR didirikan pada tahun 2009, yang berlokasi di JL PAHLAWAN NO 180 MERTOKONDO KEBUMEN Adapun ditengah maraknya kebutuhan masyarakat akan pelayanan jasa servis mobil, maka SKN bengkel dan accesories mobil turut hadir untuk memberikan pelayanan yang terbaik dan memuaskan bagi masyarakat.

2. Permasalahan

Permasalahan yang sering muncul pada sistem berjalan yang ada pada SKN Motor dimulai dari Proses penerimaan kas atas penjualan maupun servis masih dicatat dan dibukukan dalam buku besar sehingga kurang terjamin keamanan suatu data. Laporan yang disusun masih menggunakan media kertas sehingga perlu ruang dalam penyimpanan. Dokumen mudah hilang atau rusak serta penyimpanan data yang belum terstruktur dengan baik memakan kapasitas ruang data secara fisik.

3. Solusi dari Permasalahan

Berdasarkan permasalahan tersebut, penulis mencoba memberikan beberapa alternatif pemecahan masalah, diantaranya Pertama Disarankan untuk menggunakan sistem yang sudah terkomputerisasi agar data dapat terjamin keamananya. Selain itu sistem baru diharpkan dapat meminimalisir kesalahan dalam pencatatan penerimaan kas atas penjualan maupun servis sehingga dapat mempermudah dalam menysuun laporan. Selain bentuk dokumen, disarankan juga menggunakan media penyimpanan yang lebih terorganisir. Penulis menyarankan menggunakan media database sebagai tempat penyimpanan data agar terhindar dari resiko hilang ataupun rusak.

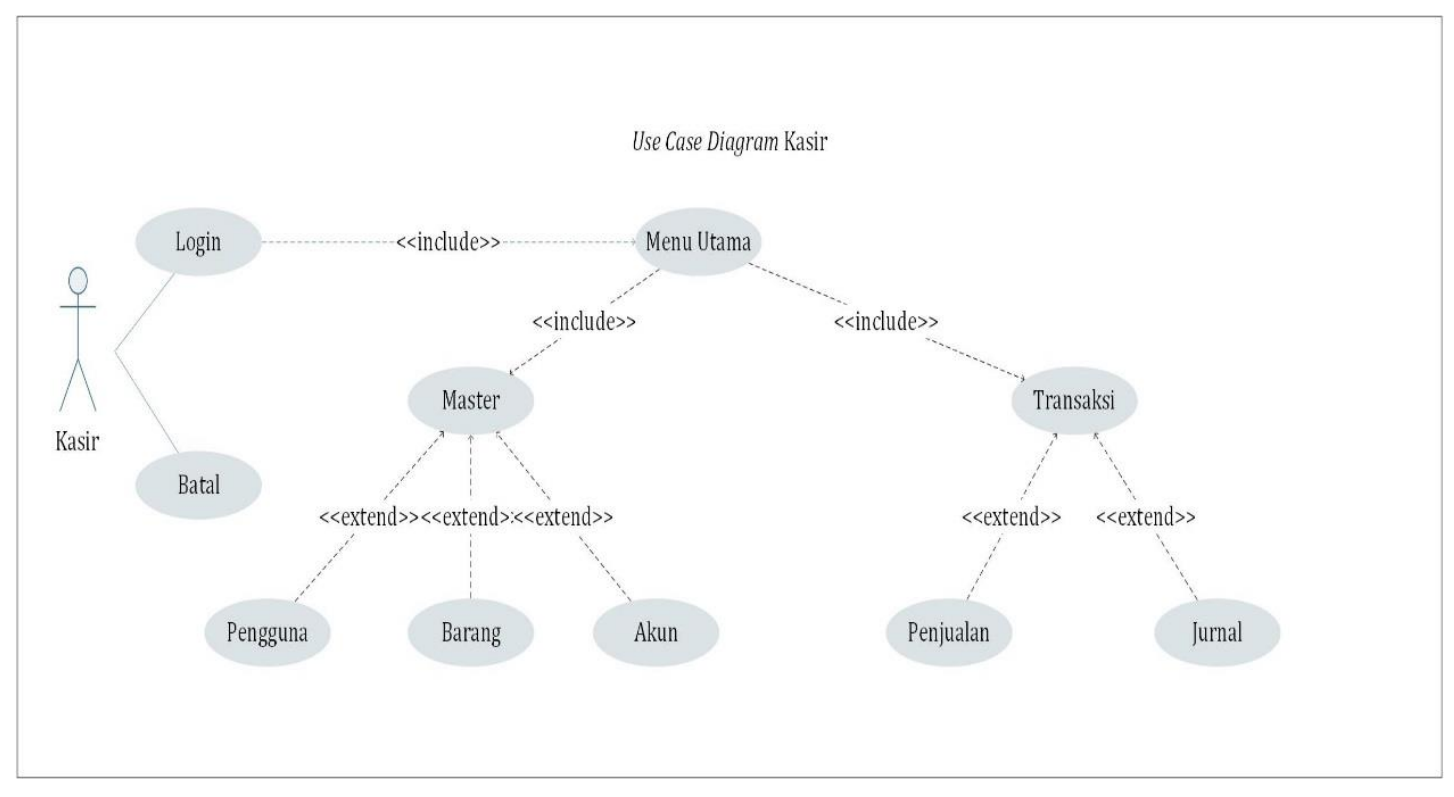

Gambar 1. Use Case Diagram Kasir 


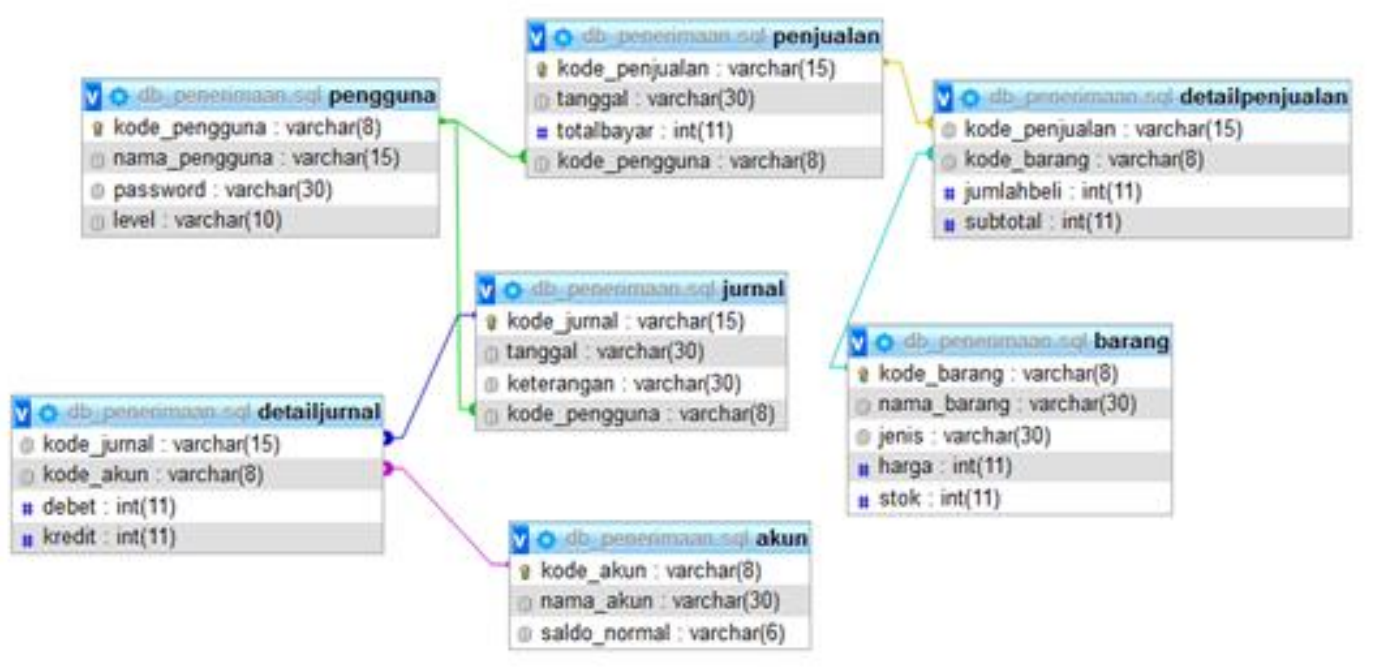

Gambar 2. Logical Record Structure

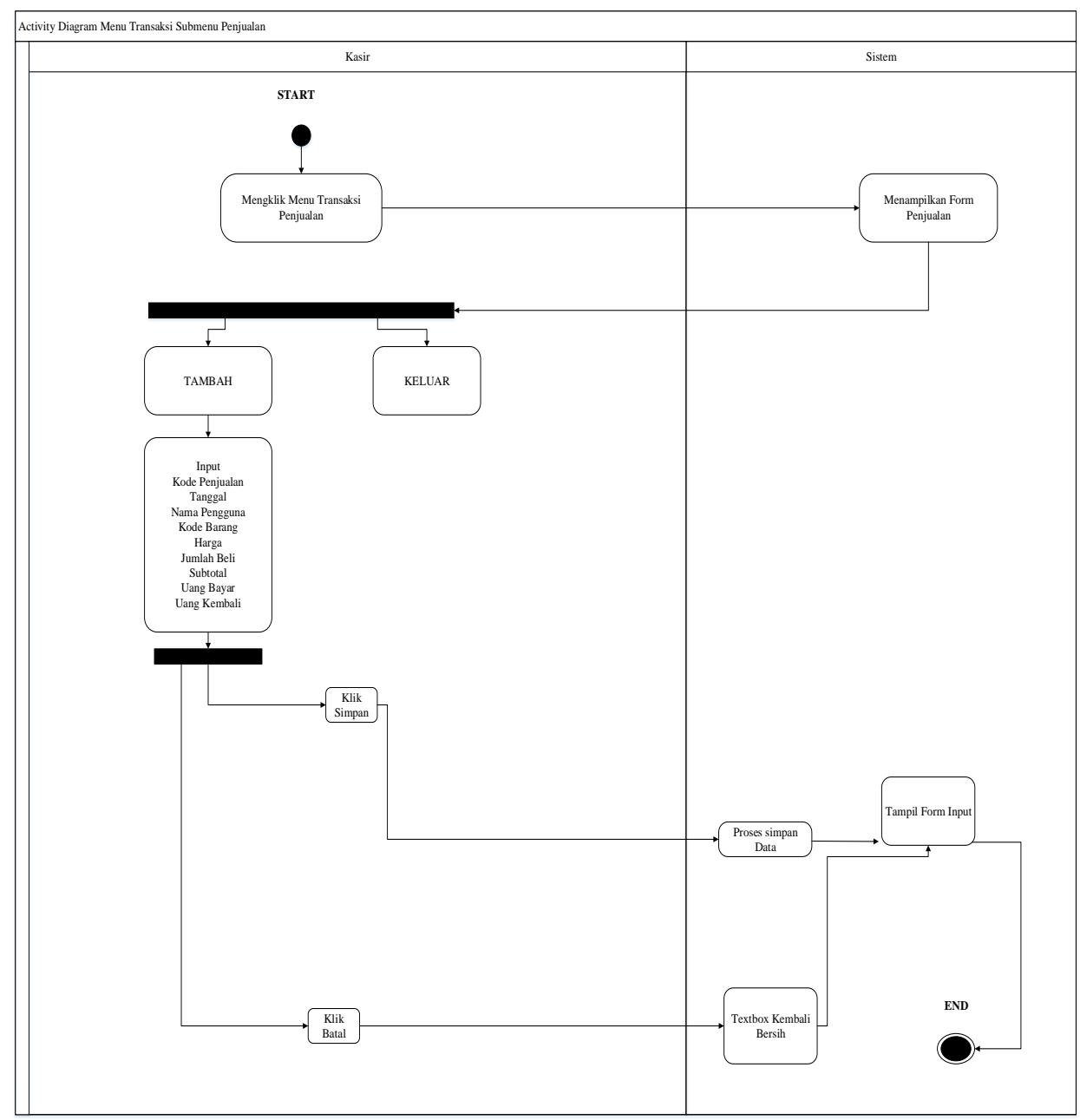

Gambar 3. Activity Diagram Transaksi Penjualan 


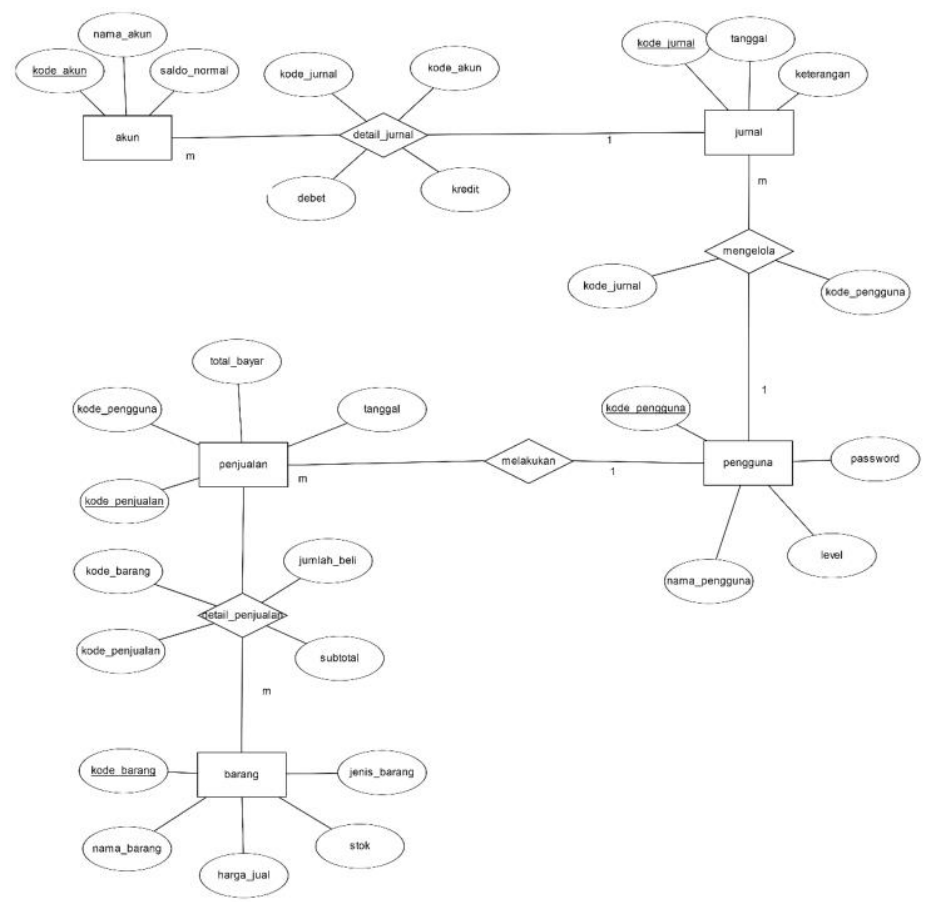

Gambar 4. Entity Relationship Diagram

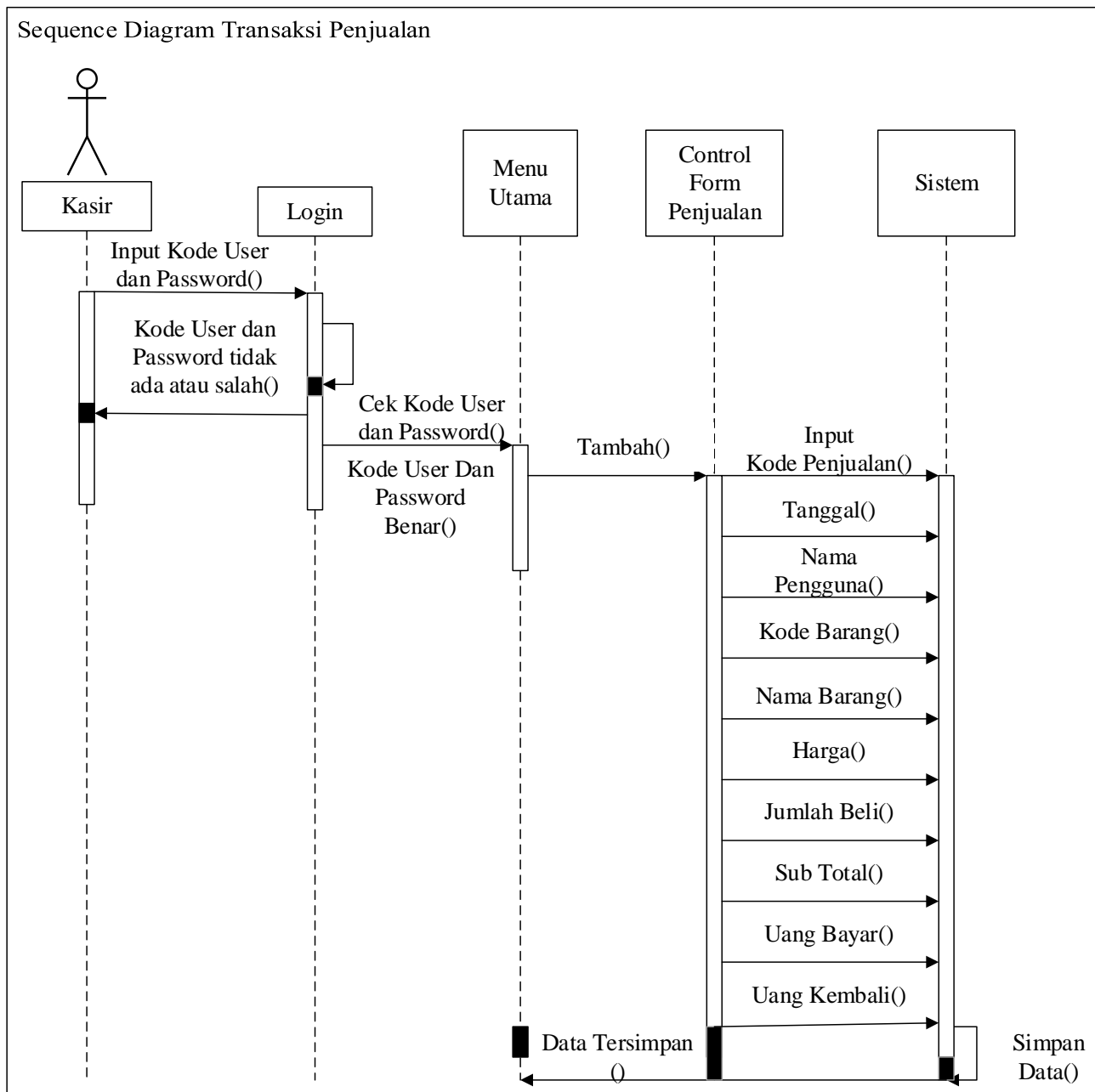

Gambar 5. Sequence Diagram 


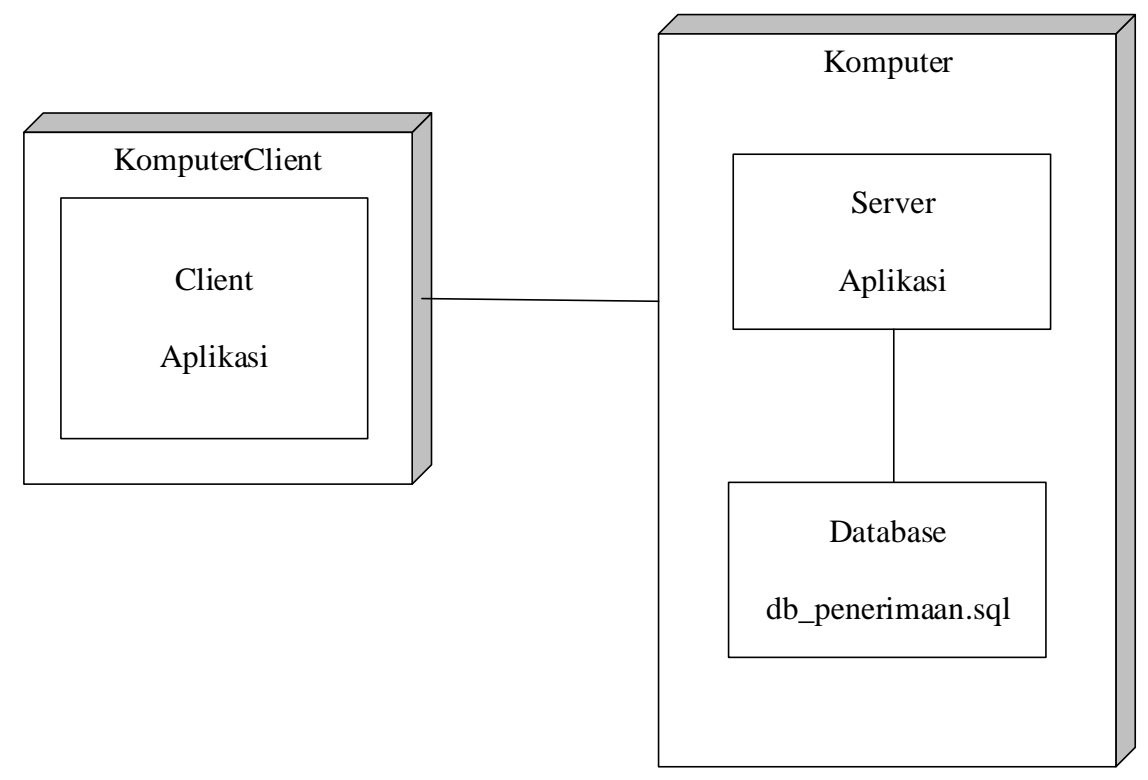

Gambar 6. Deployment Diagram

\section{SIMPULAN}

Berdasarkan hasil penelitian pada SKN Motor, penulis menarik kesimpulan sebagai berikut, Proses penerimaan kas atas penjualan yang saat ini berjalan pada SKN motor masih menggunakan buku kas sebagai media pencatatan dan pengolahan penerimaan kas atas penjualan maka dari itu penulis mengusulkan rancangan sistem berupa komputerisasi sebagai alat bantu proses pengolahan data agar lebih efektif dan efisien. Penulis menyarankan untuk menyimpan setiap dokumen dimedia database mengingat pentingnya menjaga keamanan data serta dapat meminimalisir media penyimpanan.

\section{SARAN}

Untuk Saran dari penelitian ini kedepannya bisa dilakukan, Adapun saran dari penulis yaitu usulan sistem informasi yang penulis rancang berikutnya dapat dikembangkan lagi. Penggunaan dari aplikasi ini disesuaikan berdasarkan fungsi masing-masing bagian sehingga dapat mengurangi resiko terjadinya penyalahgunaan tanggung jawab.

\section{UCAPAN TERIMA KASIH}

Penulis mengucapkan terimaksih kepada PD SKN motor yang telah mengijinkan kami untuk berkontribusi dalam menunjang usahanya.

\section{DAFTAR PUSTAKA}

Nurrahman, D., Tabrani, M., \& Ardiansyah, D. (2018). Optimasi Sistem Informasi Pembelian Bahan Baku Pada Pizza Hut Karawang. 1, 84-90.

Sukamto A, R., \& Shalahuddin, M. (2016). Rekayasa Perangkat Lunak Terstruktur Dan Berorientasi Objek (Cetakan Ke). Informatika Bandung.

Tohari, H. (2017). Astah (Analisis Serta Perancangan Sistem Informasi Melalui Pendekata Uml) (S. Wibowo (Ed.)). Cv. Andi Offset.

Yuniva, I., \& Anshori, A. (2017). Rancangan Sistem Informasi Electronic Learning Berbasis Web. 54-60.Http://Seminar.Bsi.Ac.Id/Simnasiptek/Index.Php/Simnasiptek-017/Article/View/119. 